\title{
O inimigo principal: a economia política do patriarcado ${ }^{* *}$
}

The core enemy:

the political economy of patriarchy

Desde que surgiu o movimento de libertação das mulheres, na França, nos Estados Unidos e onde mais se tenha abordado essa questão, o ponto de vista marxista foi representado por uma linha externa ao movimento feminista, compartilhada por partidos comunistas tradicionais e grupos de esquerda, e difundido no movimento por militantes oriundas desses grupos.

Em geral, as mulheres do movimento consideram essa linha insuficiente, tanto em termos de teoria quanto em termos de estratégia: 1) ela não dá conta da opressão comum às mulheres e 2) está centrada não em sua opressão, mas nas consequências dessa opressão para o proletariado.

Isso só é possível devido a uma contradição flagrante entre os princípios que essa linha reivindica e sua aplicação às mulheres. De fato, o materialismo histórico repousa na análise dos antagonismos sociais em termos de classes, elas próprias definidas por seu lugar no processo de produção. Ora, ao mesmo tempo que se pretende aplicar esses princípios ao estudo da situação das mulheres como mulheres, omite-se pura e simplesmente a análise das relações específicas das mulheres com a produção, isto é, uma análise de classes. Os resultados dessa lacuna teórica logo se percebem:

\footnotetext{
É socióloga, militante lésbica e feminista e pesquisadora do Conseil National de Recherche Scientifique (CNRS, França).

** Publicado em Partisans, n esp., "Libération des femmes: année zero", nov. 1970. Incluído no livro L'ennmi principal, vol. 1: L'économie politique du patriarcat (Éditions Syllepse, 2013). Direitos concedidos pela autora e editora Syllepse. Traduzido por Patrícia C.R. Reuillard. Revisão técnica da tradução por Luis Felipe Miguel.
} 
- a opressão das mulheres é vista como uma consequência secundária à (e derivada da) luta de classes tal como definida atualmente - ou seja, apenas da opressão dos proletários pelo capital;

- a opressão das mulheres onde o capitalismo enquanto tal foi destruído é atribuída a causas puramente ideológicas - o que implica uma definição não marxista e idealista da ideologia como um fator que pode subsistir na ausência de uma opressão material que ela serve para racionalizar.

- Esses postulados entram em contradição com a dinâmica do movimento; a tomada de consciência, por parte das mulheres, de uma dupla exigência, teórica e política: buscar as razões estruturais que fazem com que a abolição das relações de produção capitalista em si não baste para libertá-las; constituir-se como força política autônoma.

Recém-surgido, o movimento já se confronta com uma contradição. No exato momento em que se constitui como força revolucionária, a única análise que insere a luta das mulheres em uma perspectiva revolucionária global elimina a primeira dessas exigências - a busca das causas da opressão específica das mulheres - e não oferece nenhuma base teórica à segunda: ela permite, mas não funda a necessidade da constituição de um movimento autônomo.

As consequências dessa contradição se fazem sentir imediatamente no movimento por um mal-estar geral, por tendências antagônicas e por dificuldades de funcionamento, ocasionados pela impossibilidade de definir uma prática coerente enquanto houver um hiato entre a teoria de referência e a opressão real que se combate, e enquanto a própria existência do movimento como tal não estiver solidamente, isto é, teoricamente estabelecida.

Portanto, a consequência prática da existência dessa linha é que ela funciona como um freio ao movimento, que, evidentemente, não é fortuito. Nosso objetivo, aqui, não é deslindar os mecanismos que levaram à sua adoção pelas próprias mulheres ${ }^{1}$ nem demonstrar como ela constitui mais uma prova da existência de interesses objetivos - e não limitados à classe capitalista - na opressão das mulheres. Basta dizer que, em razão de seu

1 Que são os mecanismos de alienação e de falsa consciência servindo para manter a opressão: portanto, as mulheres não são responsáveis, mas vítimas da opressão. 
papel objetivo de freio à libertação das mulheres, essa linha só pode advir de grupos interessados na sujeição feminina e que, devido a seu caráter não científico, não pode ser considerada senão como a roupagem marxista das teorias que justificam essa sujeição, ou seja, como uma ideologia. Porém, mais uma vez, não pretendemos fazer uma crítica sistemática a essa linha - o que será feito em outra ocasião -, mas tentar fornecer ao movimento o que ele precisa crucialmente agora: as bases para uma análise materialista da opressão às mulheres.

Essa preocupação corresponde de fato a uma necessidade objetiva do movimento, já que, nestes anos (1969-1970), estão surgindo simultaneamente, em pontos geográficos muito distantes e escritos por feministas sem contato umas com as outras, ensaios que tentam compreender a opressão às mulheres a partir de sua base material: sobretudo os de Margaret Bentson (1970 [1969]) e Larguia (1970)2.

Para sobreviver, toda sociedade deve criar bens materiais (produção) e seres humanos (reprodução). Esses ensaios centram a análise da opressão às mulheres em sua participação específica na produção (e não mais apenas na reprodução), por meio do trabalho doméstico e da criação dos filhos, analisados como tarefas produtivas. Desse modo, eles constituem o embrião de uma análise feminista radical baseada nos princípios marxistas: ao rejeitar as pseudoteorias, que fazem da família antes de tudo um lugar de doutrinação ideológica dos "futuros produtores", destinado a apoiar indiretamente apenas a exploração capitalista, e ignoram sua função econômica, mostram que na família se dá uma exploração econômica: a das mulheres. Após exporem que as tarefas domésticas e a criação dos filhos cabem exclusivamente às mulheres e que elas não são remuneradas, esses estudos concluem que as mulheres têm, por conseguinte, uma relação específica com a produção, comparável à servidão. Entretanto, não basta ficar nisso. É preciso ainda analisar as relações entre a natureza dos bens e serviços domésticos e o modo de produção desses bens e serviços, proceder a uma análise de classe das mulheres e, a partir dela, traçar as linhas gerais das perspectivas políticas do movimento, em termos de objetivos, mobilização e alianças políticas.

2 Ver também Wittg et al. (1970), em que se destaca particularmente a noção de trabalho servil. 


\section{Relações de produção de que as mulheres participam}

Todas as sociedades atuais, inclusive as "socialistas", repousam, no que diz respeito à criação dos filhos e aos serviços domésticos, no trabalho gratuito das mulheres. Esses serviços são fornecidos apenas no âmbito de uma relação particular com um indivíduo (marido), são excluídos do domínio da troca e, consequentemente, não têm valor. Não são remunerados. Os benefícios recebidos pelas mulheres são independentes do trabalho fornecido e não são pagos em troca deste, ou seja, como um salário ao qual o trabalho efetuado dá direito, mas como uma doação. A única obrigação do marido - que evidentemente é de seu interesse - é prover as necessidades de sua mulher ou, em outras palavras, manter sua força de trabalho.

Nos textos norte-americano e cubano citados, subsiste uma ambiguidade ou, antes, um resquício da ideologia dominante: enquanto se reconhece que o trabalho doméstico é produtivo, sugere-se ou afirma-se explicitamente, no entanto, que seu não valor, sua não remuneração e sua exclusão do campo da troca resultariam da própria natureza dos serviços domésticos: isso se baseia e é expresso em dois postulados. As mulheres: 1) seriam "estruturalmente não responsáveis pela produção das mercadorias", "excluídas do mundo do sobreproduto" (mais-valia) (Bentson, 1970 [1969]); 2) estariam limitadas a atividades que produzem apenas "valores de uso" e não "valores de troca", não criando "sobreproduto" (Larguia, 1970).

Afirmamos, ao contrário, que não é a natureza dos trabalhos efetuados pelas mulheres que explica suas relações de produção, longe disso, mas que são essas relações que explicam que seus trabalhos sejam excluídos do mundo do valor. São as mulheres que são excluídas do mercado (da troca) enquanto agentes econômicos e não sua produção.

\section{As relações de produção acima descritas (não remuneração) como} aplicadas ao trabalho doméstico não se limitam às produções consumidas na família (criação dos filhos, tarefas domésticas), mas se aplicam também às produções destinadas ao mercado quando nela produzidas.

A participação das mulheres na criação de mercadorias e de produções vitais é atestada em toda a literatura etnológica e constitui uma pedra no jardim dos ideólogos que tentam explicar o status inferior das mulheres por seu papel secundário - ao menos "nas origens" - na sobrevivência da espécie. Não cabe aqui discutir o fenômeno da construção da ideologia "naturalista" que embasa o sistema em mito das origens, projetado à vontade em todos os 
momentos da história, mito de que o próprio Engels foi vítima. Basta dizer que o conjunto dos documentos etnológicos demonstra que a importância econômica das produções efetuadas pelas mulheres ou pelos homens não tem relação com a preeminência social de um ou do outro sexo e que, ao contrário, toda evidência, tanto etnológica quanto sociológica, indica uma relação inversa: as classes dominantes obrigam as classes que elas subjugam a efetuar o trabalho produtivo.

Hoje em dia, na França, o trabalho das mulheres não é remunerado quando se aplica aos produtos de uso doméstico e também a produções para o mercado. Isso se verifica em todos os setores em que a unidade de produção é a família (em oposição ao próprio negócio ou à fábrica), isto é, na maior parte da agricultura, no comércio e nas atividades por conta própria. Seu trabalho não é em nada marginal: em 1968, as mulheres de agricultores consagravam em média quatro horas por dia aos trabalhos agrícolas (Bastide, 1969). A "crise do campo" se deve, em grande parte, ao fato de que as mulheres não querem mais casar com agricultores. Ora, é opinião geral que "uma fazenda não pode funcionar sem uma mulher". Michelet dizia que, quando um proprietário rural não podia pagar um empregado, ele se casava. Isso ainda é verdade: "Michel precisaria de alguém para ajudá-lo, mas não consegue encontrar uma empregada. Se ao menos ele pudesse se casar..." ${ }^{.} \mathrm{Na}$ França, as atribuições das mulheres na propriedade rural variam de região para região. Cuidar dos animais - aves, porcos etc. - é uma constante; quanto ao resto, elas servem para tudo - auxiliam, efetuam os trabalhos subalternos, sujos, difíceis, não mecanizados (particularmente a ordenha das vacas à mão, trabalho tão exigente e com horários tão desagradáveis que algumas mulheres de hoje registram no contrato de casamento que não se comprometem a fazê-lo; os homens se ocupam dessa tarefa, quando mecanizada). Com frequência, a única fonte de dinheiro líquido, que possibilita consumos não produzidos na fazenda, provém da venda de produções tipicamente femininas: leite, ovos, aves. Mas, independentemente das atribuições da mulher na propriedade, seu trabalho é absolutamente necessário, já que um homem sozinho não pode manter uma fazenda sem um trabalho dobrado; em última hipótese, não pode simplesmente manter uma fazenda, mesmo que se limite à produção agrícola.

3 Comunicação pessoal da mãe de Michel, agricultor solteiro do sudoeste da França. 
O trabalho gratuito de uma mulher conta, portanto, na economia geral da propriedade rural, assim como contava o trabalho gratuito do segundo filho, irmãos ou irmãs deserdados em sentido literal, e o das crianças. Ainda que, na maioria dos casos, hoje eles exijam um salário para não ir embora, ou se vão, é inútil lembrar que os explorar era regra em todos os setores da economia até a industrialização (fim do século XVIII) e, na agricultura, até a última guerra.

Histórica e etimologicamente, a família é uma unidade de produção. Em latim, familia designa o conjunto das terras, escravos, mulheres e crianças submetidos ao poder (então sinônimo de propriedade) do chefe de família. Nessa unidade, o pai é dominante, pois o trabalho dos indivíduos sob sua autoridade lhe pertence; em outras palavras, a família é o conjunto dos indivíduos que devem seu trabalho a um "chefe".

Como a família se baseia na exploração dos aparentados ou afiliados pelo casamento, tal exploração subsiste em qualquer lugar em que o modo de produção permaneça familiar. No Marrocos, por exemplo: "No mundo rural, as mulheres se ocupavam da colheita das frutas e do cuidado dos animais. Elas não recebiam nenhuma remuneração por seu trabalho; tinham direito ao seu sustento pelo chefe de família” (Nouacer, 1969).

Em 1970, 7 milhões de mulheres eram declaradas "ativas" na França, ou seja, participavam da produção. Desse total, 1 milhão era "ajudante familiar" ${ }^{*}$, o que significa que não eram remuneradas; quase oito em cada dez mulheres não remuneradas trabalhavam na agricultura. $\mathrm{O}$ status de "ajudante familiar" é a consagração da exploração familiar, pois institucionaliza a situação de que produtores sejam não pagos, isto é, que o lucro de sua produção pertença a seu parente, marido ou pai. Ele foi "inventado" após a guerra para permitir que esses trabalhadores recebessem "vantagens sociais". Contudo, muitas mulheres de agricultores, de comerciantes e de trabalhadores por conta própria continuam se declarando "sem profissão". Assim, o número de mulheres que participa da produção de mercadorias na "propriedade" familiar é com certeza muito superior ao número de mulheres recenseadas como "ajudantes familiares". Avaliando por baixo, em 40\%, chegaríamos a uma avaliação de 1.400 milhão em 14 milhões de mulheres adultas (entre

4 * Esse status é reservado às pessoas com no mínimo dezesseis anos, ascendentes, descendentes, irmãos ou parentes de primeiro grau do dono da propriedade agrícola ou de seu cônjuge que vivem na propriedade e participam dela sem serem assalariadas [N. T.]. 
17 e 64 anos) sujeitas a essas relações de produção, ou seja, uma em cada dez mulheres em 1970.

A gratuidade do trabalho das mulheres continua sendo aceita ainda que a gratuidade do trabalho dos filhos seja questionada: é cada vez mais frequente, quando casais de gerações diferentes convivem na propriedade, que o filho exija ser pago por seu trabalho - e não mais "recompensado" apenas pela manutenção de sua força de trabalho -, embora a sugestão de que sua mulher possa exigir o mesmo, e de que o casal receba dois salários por dois empregos, não seja absolutamente aceita. A gratuidade do trabalho dos homens é rechaçada (em 1970, resta apenas um ajudante familiar em 43 homens "ativos", contra uma em sete mulheres "ativas"), ao passo que a gratuidade do trabalho das mulheres é institucionalizada não somente na prática, mas também na contabilidade do Estado (status de ajudante familiar) e nas reivindicações dos partidos de oposição: o Movimento de Defesa das Propriedades Familiares (Modef) 5 exige que se assegure a cada propriedade familiar uma renda equivalente a um salário. A implicação disso é que o trabalho da mulher, incorporado à produção do casal, não merece salário ou, antes, já que a produção da mulher é trocada pelo marido como sendo sua, que o trabalho da mulher pertence ao marido.

\section{Não há diferença entre os serviços domésticos realizados pelas mulheres e os outros bens e serviços ditos produtivos, realizados e consumidos na família.}

Na economia rural clássica, a maioria dos bens consumidos pela família é produzida por ela, que absorve diretamente uma parte de sua própria produção. Ora, essa produção também é comercializável, isto é, não há distinção entre valor de uso e valor de troca. O mesmo bem que é consumido e que tem, portanto, um valor de uso para a família também tem naturalmente um valor de troca, visto que pode ser vendido no mercado; por outro lado, se não fosse produzido internamente, deveria ser substituído por seu equivalente comprado no mercado.

Por essa razão, o autoconsumo rural é considerado uma renda pelos interessados e uma produção pela contabilidade nacional. Resta saber se um porco consumido pela família deve ser avaliado por seu preço de custo - pelo preço de venda, ou seja, pelo que se deixou de ganhar na propriedade -ou

5 O Modef era um pequeno movimento camponês vinculado ao Partido Comunista Francês. 
por seu preço de substituição - pelo preço de compra se não tivesse sido produzido, ou seja, pelo que se deixou de perder da unidade de consumo.

Quando produtor e consumidor são um só, como na família rural, percebe-se que há um continuum entre produção e consumo: o trigo é semeado para ser consumido; é moído porque não pode ser consumido em grãos; é cozido porque não pode ser consumido como farinha - e nenhuma dessas operações tem utilidade sem as outras, já que o objetivo é o consumo final. Portanto, é absurdo interromper esse processo. Todavia, é o que acontece quando se contabiliza como produção uma parte desse processo - da semeadura à produção de farinha - e se considera não produtiva a outra parte, por exemplo, o cozimento do pão. Ou todo o trabalho agregado ao produto autoconsumido é produtivo ou nada dele é produtivo. Esta última hipótese é absurda, pois o porco consumido poderia ter sido vendido no mercado, mas deveria ter sido substituído por seu equivalente em alimentos comprados. É o que ocorre com os agricultores que praticam a monocultura e, mais ainda, com todos os trabalhadores que não produzem nada que podem consumir: esse fato oculta que o objetivo de toda produção é, em última análise, o consumo, porque os produtos devem ser trocados duas vezes antes que se possa consumi-los (venda do produto do trabalho e compra do produto para consumir). O que interrompe o continuum produção-consumo não é que certas atividades necessárias à realização do objetivo final - o consumo - sejam não produtivas, mas o fato de que, quando as produções são especializadas, o consumo - meta final de toda produção - é mediado pela troca.

O exemplo do autoconsumo rural ilustra bem, portanto, que não há nenhuma diferença de natureza entre as atividades ditas "produtivas" (como a engorda do porco) e as atividades domésticas "não produtivas" (como seu cozimento).

Em resumo, homens e mulheres criam juntos:

1. valores de uso que são virtualmente valores de troca: ambos produzem leite, ovos, produtos agrícolas para seu consumo e para troca; o nível de consumo e a quantidade de dinheiro líquido desejados determinam o que vai para o mercado e o que é autoconsumido;

2. valores de uso que são contabilizados na produção (no produto nacional bruto);

3. valores de uso "produtivos" que não diferem dos valores de uso "não produtivos" criados pelo trabalho puramente doméstico; fazem parte 
do mesmo processo de criação e de transformação dos produtos brutos (incidem sobre os mesmos materiais brutos no que concerne à produção de alimentos consumíveis) e têm a mesma finalidade: 0 autoconsumo ${ }^{6}$.

\section{Assim como há continuidade e não cesura entre as atividades que objetivam o autoconsumo, denominadas produtivas, e as atividades que objetivam o autoconsumo, denominadas não produtivas (as atividades domésticas), há continuidade entre os serviços fornecidos gratuitamente pelas mulheres e os serviços comercializados.}

Atualmente, muitas operações de transformação das matérias-primas brutas em produtos consumíveis são industrializadas: aquelas que outrora faziam parte das atividades domésticas são agora efetuadas fora de casa, tais como a fabricação de pão, de vestuário, de conservas etc. O padeiro, as fábricas de tecidos e de confecção vendem hoje um trabalho que antes as mulheres faziam de modo gratuito. Essas fabricações são consideradas como produções e contabilizadas oficialmente no produto nacional: o trabalho agregado a elas é considerado produtivo, e os indivíduos que o efetuam, produtores, o que não acontecia quando eram criadas pelo trabalho gratuito das mulheres.

As mulheres não efetuam mais a maioria dessas produções; elas não diferem, em natureza, das produções domésticas - limpeza, cozinha, cuidado dos filhos - que continuam sendo quase sempre feitas gratuitamente por elas. Mais uma prova de que a gratuidade não depende da natureza dos trabalhos é o fato de que, quando as mulheres efetuam esses serviços fora de casa, eles são remunerados.

Quando esses serviços não podem ser fornecidos pelas mulheres em casa, a família deve procurá-los venalmente.

$\mathrm{Na}$ verdade, todos os serviços domésticos existem no mercado: alguns comércios de fiambres e restaurantes vendem pratos prontos, as creches e as babás atendem as crianças, as empresas de limpeza e os domésticos executam os trabalhos de manutenção etc.

A alimentação constitui o principal gasto do orçamento doméstico (de $50 \%$ a $80 \%$ ). A família pode escolher entre comprar a comida pronta e pagar

6 Ernest Mandel (1962) confirma que os termos valor de troca e valor de uso não designam nem a natureza, nem o valor intrínseco, nem a produtividade do trabalho agregado às diversas produções, mas simplesmente a utilização que dele se faz: o consumo imediato ou mediado pela troca. 
o valor agregado à forma bruta pelo trabalho venal do comerciante, do dono de restaurante etc., ou comprá-la bruta e aplicar o trabalho necessário para torná-la pronta para consumo. A maioria dos gastos efetuados nesse item é consagrada à compra de matérias-primas brutas.

Pode-se dizer que a família efetua ela mesma a produção dos bens finais de consumo, da mesma maneira que uma empresa produz seus bens finais. Para isso, ela utiliza essencialmente o trabalho (doméstico), máquinas (os bens duráveis) e matérias-primas (os produtos intermediários, comprados diretamente das empresas produtoras), que são transformadas pela própria família com uma determinada quantidade de trabalho e de capital. Vista desse modo, a família só se distingue da empresa porque acrescenta à produção (única função da empresa) uma atividade de consumo (objetivo da produção efetuada pela própria família com os bens produzidos pela empresa) (Wolfelsperger, 1970, p. 20).

Para o produtor, como a finalidade da produção é o consumo ou de sua produção na economia de subsistência, ou de outros produtos na economia de especialização (assim como, para o comprador, a finalidade da produção é o consumo dessa produção), o salário derivado da troca de uma produção especializada ou da força de trabalho no mercado não basta para cumprir essa finalidade. Ela é cumprida em dois momentos: na compra das matérias-primas do consumo graças ao trabalho assalariado; na transformação dessas matérias-primas em produto diretamente consumível graças ao trabalho doméstico.

Portanto, temos, de um lado, um trabalho interno que fornece uma certa quantidade de bens diretamente consumíveis; do outro, um trabalho externo que traz uma certa renda monetária. Mas qual é a utilização dessa renda? Admitimos que ela reside não diretamente na utilidade dos consumos que permite, como na teoria tradicional, mas, de acordo com nossas hipóteses, na contribuição dessa renda para a produção de bens finais de consumo, isto é, na contribuição de bens capitais adquiridos graças à renda (matéria-prima e bens duráveis) para essa produção (Wolfelsperger, 1970, p. 22).

O que esse economista burguês não menciona é que se a maioria dos "lares" prefere comprar a comida bruta é porque o trabalho doméstico é gratuito e inteiramente fornecido pelas mulheres. Podem se opor esses fatos à ideologia segundo a qual apenas o salário do marido paga o consumo total do lar, enquanto a dona de casa "não ganha seu sustento". 
Na França, em 1955, em 105 bilhões de horas trabalhadas, 43 eram consagradas ao trabalho remunerado e 45 ao trabalho doméstico não assalariado (Dayre, 1955) e, em cinquenta anos, nem os dados brutos nem as razões de um tipo de trabalho a outro mudaram. A contabilidade nacional sueca incorpora esse trabalho gratuito ao produto nacional bruto e o avalia em um quinto deste 7 . Em 1958, as francesas casadas forneciam em média 60 horas de trabalho doméstico gratuito por semana (Girard, 1958): as mulheres sem filhos, 35 horas; com um filho, 52 horas; com dois filhos, 64 horas; e com três filhos, 70 horas (Insee, 1973).

Para concluir, a exclusão do trabalho das mulheres do âmbito da troca não resulta da natureza de sua produção, visto que seu trabalho gratuito se aplica: 1) à produção de bens e serviços que chegam e são trocados no mercado (na agricultura, nos negócios por conta própria, no comércio); 2) à produção de bens e serviços remunerados quando efetuados fora da família e não remunerados na família. Isso se aplica a todas as produções da família, independentemente de sua natureza.

\section{Hoje, a apropriação da força de trabalho das mulheres tende a se limitar à exploração (o fornecimento gratuito por elas) do trabalho doméstico e à criação dos filhos.}

Com a industrialização, a família perde sua função de unidade de produção, salvo em certos setores. A industrialização significa principalmente que a produção destinada ao mercado não pode mais ser efetuada na família. Consequentemente, mais nada dessa produção pode incorporar o trabalho gratuito da mulher ou de seus filhos. Em outras palavras, o trabalho das mulheres não pode mais ser incorporado às produções destinadas à troca quando efetuadas fora de casa. Com a generalização desse modo de produção, diminui o número de trabalhadores independentes que podem trocar o trabalho de sua mulher, ao passo que aumenta o dos assalariados que não podem trocá-lo.

Nos setores em que toda a produção destinada à troca é produzida no modo salarial, o trabalho gratuito da mulher só pode ser aplicado às produções não destinadas à troca. Ou seja, o modo de produção familiar - a exploração do trabalho gratuito da mulher - não pode mais se aplicar às produções destinadas à troca. Convém esclarecer, entretanto, que se trata

7 As bases dessa estimativa são desconhecidas. 
de troca operada pelo marido. O trabalho agrícola da mulher, por exemplo, não lhe é pago se for feito em casa: ela não pode trocar sua produção familiar no mercado. Portanto, não dispõe de sua força de trabalho. Quem dela dispõe é o marido, único a poder trocar a produção da mulher no mercado. Do mesmo modo, ela não dispõe de sua produção doméstica quando realizada em casa e só pode trocá-la fora. Assim, as produções das mulheres têm sempre um valor de troca - podem ser trocadas por elas - salvo no contexto familiar. Com a industrialização, a produção familiar se restringe ao trabalho doméstico: chama-se de trabalho doméstico aquilo ao que se reduz a produção gratuita da mulher.

A consequência imediata da impossibilidade de explorar totalmente a força de trabalho das mulheres é sua entrada na indústria como assalariadas. Desde 1900, a proporção de mulheres ativas é a mesma de hoje. No entanto, a apropriação de sua força de trabalho pelo marido é tão absoluta que, mesmo quando ela trabalha fora de casa, seu salário pertence ao marido. A partir de 1907, a mulher dispõe - legalmente - de seu salário, mas, de fato, os regimes matrimoniais anulam essa concessão (já que todos os ganhos entram na comunhão de bens, que só o marido pode utilizar). Até 1965, o marido pode se apropriar de toda a força de trabalho da mulher, pois pode impedi-la de trabalhar fora.

Como essas disposições foram abolidas em 1965, pode-se dizer que, a partir daí, a mulher recuperou parcialmente sua força de trabalho. Mesmo podendo legalmente trabalhar fora de casa, na prática ela não é livre, pois o marido continua se apropriando de uma parte dessa força de trabalho, já que ela deve "assumir suas obrigações familiares", isto é, fazer gratuitamente o trabalho doméstico e se ocupar dos filhos. Trabalhar fora não somente não a dispensa das tarefas domésticas, mas, além disso, não deve atrapalhá-las. Portanto, para ter uma certa independência econômica, a mulher só é livre para ter uma dupla jornada de trabalho. A situação da mulher casada que trabalha evidencia bem a apropriação estatutária de sua força de trabalho. De fato, o fornecimento de trabalho doméstico não é mais justificado pela troca econômica à qual se assimila abusivamente a servidão da mulher "à casa": não se pode mais defender que o trabalho doméstico é efetuado em troca do sustento, nem que o sustento é o equivalente do salário, e que esse trabalho é, portanto, pago. As mulheres que trabalham se sustentam sozinhas e efetuam esse trabalho em troca de nada. 
Ademais, quando um casal calcula o que ganha uma mulher que trabalha "fora", ele deduz os gastos com o cuidado dos filhos, os impostos extras etc. apenas do salário dela, em vez de subtraí-los da renda total do casal. Isso demonstra quese considera que esses consumos devem: 1) ser gratuitos, ao contrário da moradia, transporte etc., que não são deduzidos dos ganhos; 2) ser produzidos exclusivamente pela mulher, já que uma parte de seu salário é considera nula, servindo para pagar o que ela deveria ter feito de modo gratuito.

Ao fim desse cálculo, descobre-se geralmente que a mulher não ganha "quase nada".

Na França, de acordo com o recenseamento de 1968, 37,8\% das mulheres casadas trabalham fora de casa (Rouxin, 1970).

\section{A partir desses dados, é possível agora esboçar os princípios de uma análise de classes.}

Constata-se a existência de dois modos de produção em nossa sociedade: a maioria das mercadorias é produzida no modo industrial; os serviços domésticos, a criação dos filhos e algumas mercadorias são produzidos no modo familiar. O primeiro dá lugar à exploração capitalista. $\mathrm{O}$ segundo, à exploração familiar, mais exatamente, patriarcal.

307 mil homens (ajudantes familiares) em cerca de 15 milhões de homens adultos são submetidos à exploração familiar em 1970: eles efetuam - principalmente na agricultura - serviços profissionais gratuitos em casa. Todas as mulheres casadas, ou seja, a qualquer momento $80 \%$ das mulheres adultas (nos dias de hoje, mais de 90\% das mulheres estão ou já estiveram casadas ou em relação de concubinato ao longo de sua vida), são submetidas a essa exploração: elas fornecem gratuitamente pelo menos serviços domésticos e criação dos filhos em casa. O status de criança ou de segundo filho mais velho, base da propriedade familiar para os homens, é temporário, ao passo que o status de mulher é permanente. Além disso, os ajudantes familiares do sexo masculino não são explorados em sua condição de homens, ao passo que é na condição de mulheres (esposas) que elas o são. Embora o trabalho agrícola, manual ou comercial gratuito possa ser fornecido tanto por homens quanto por mulheres por serem membros da família, o trabalho doméstico gratuito é efetuado exclusivamente por elas, na qualidade de mulheres do chefe de família. 
A apropriação do trabalho das mulheres se aplica a todas as produções familiares quando a família é a unidade de produção para o mercado (mulheres de agricultores, trabalhadores por conta própria, comerciantes: cerca de 1 milhão em 15,5 milhões de mulheres adultas em 1970). Ela se aplica apenas às produções domésticas quando a família não produz mais diretamente para o mercado (mulheres de assalariados).

No primeiro caso, há uma apropriação total da força de trabalho da mulher; no segundo, é total se ela não trabalhar fora, ou parcial caso trabalhe (37,8\% das mulheres são "ativas" em 1970), mas se deve deduzir dessa cifra as ajudantes familiares, isto é, em torno de 800 mil mulheres de agricultores, artesãos e comerciantes.

Portanto, a maioria das mulheres casadas não tem renda independente e trabalha por seu sustento. A diferença entre esse modo de produção e o modo de produção capitalista salarial não se deve à quantidade dos serviços prestados pelo trabalho nem à diferença em valor entre um salário e um sustento, mas à própria relação de produção.

$\mathrm{O}$ assalariado vende sua força de trabalho por um salário fixo que depende do serviço fornecido, que também é fixo, delimitado em montante (horas de trabalho) e em tipo (qualificação). As equivalências são determinadas por uma tabela fixa (isto é, um preço estabelecido pela oferta e pela demanda globais de trabalho no mercado no sistema capitalista), a qual não é submetida à boa vontade das partes; as figuras do empregador e do empregado não influem nos termos do contrato e são intercambiáveis: o trabalho fornecido tem um valor universal, e é esse valor que o empregador compra e que o assalariado pode negociar, porque pode levar sua força de trabalho para outro lugar. O fato de que são serviços precisos que são comprados leva a que o assalariado possa melhorar seu ganho se aumentar ou qualificar seu serviço.

Os serviços da mulher casada, em contrapartida, não são precisos: dependem da vontade do empregador, o marido. Tampouco são remuneradas por uma tabela fixa: seu sustento não depende do trabalho efetuado, mas das posses e da boa vontade do marido. Para uma mesma tarefa, como a criação de três filhos, o sustento da mulher de um operário e da mulher de um alto executivo pode variar de um a dez. Para o mesmo sustento, ao contrário, a mulher fornece serviços muito diferentes conforme as necessidades do marido. Assim, as tarefas de trabalho doméstico das esposas de burgueses são reduzidas em prol de tarefas de representação social. Como o sustento recebido não tem relação com as tarefas 
fornecidos, as mulheres não têm como melhorar seus serviços para aumentar o nível de vida, e sua única saída consiste em fornecer as mesmas tarefas a um homem mais rico: a consequência lógica do não valor de seu trabalho é a corrida para fazer um bom casamento. Porém, embora o casamento com um homem da classe proprietária possa elevar o nível de vida de uma mulher, ele não a inclui nessa classe. Ela própria não possui os meios de produção. Seu nível de vida não depende, portanto, das relações de produção de classe com os proletários, mas das relações de produção de servidão com seu marido. As mulheres de burgueses que se separam precisam ganhar a vida, na imensa maioria dos casos, como assalariadas: passam então a ser concretamente - com a desvantagem extra da idade e da falta de qualificação profissional - as proletárias que eram virtualmente.

O não valor do trabalho da mulher é atestado pela ausência de vínculo entre os serviços prestados e o sustento recebido. Ele é consequência da impossibilidade de trocar esse trabalho, ela própria consequência de sua impossibilidade de trocar de empregador (basta comparar o número de mulheres divorciadas que se casam de novo ao número de trabalhadores que mudam de emprego em um mesmo ano). O contrato pode ser rompido unilateralmente desde que as mulheres continuem a fornecer os serviços adequados (cuidar dos filhos; apenas o sustento deles é pago pela pensão alimentar, quando é).

Em resumo, o assalariado depende do mercado (de um número teoricamente ilimitado de empregadores), ao passo que a mulher casada depende de um indivíduo. Enquanto o assalariado vende sua força de trabalho, a mulher casada dá a sua: exclusividade e gratuidade estão intimamente ligadas.

\section{O fornecimento gratuito de trabalho no contexto de uma relação global e pessoal (o casamento) constitui precisamente uma relação de escravidão.}

Uma vez que menos de $10 \%$ das mulheres de mais de 25 anos são solteiras, pode-se dizer que as chances de uma mulher estar casada em um momento qualquer de sua vida são tão grandes que todas as mulheres estão fadadas a entrar nessas relações de produção. Como grupo efetivamente submetido a essa relação de produção, elas constituem uma classe; como categoria de seres humanos destinados por nascimento a entrar nessa classe, elas constituem uma casta ${ }^{8}$.

8 De modo revelador, os termos mulher e esposa são sinônimos. Do mesmo modo, "escravo vem de eslavo, nome de um povo... Como muitos eslavos se tornaram servos, a palavra'eslavo'foi empregada como sinônimo de servo" (Littré, 1958). 
A apropriação e a exploração do trabalho das mulheres no casamento constituem a opressão comum a todas elas. Como seres destinados a se tornar "a mulher de" alguém, as mulheres destinadas à mesma relação de produção formam uma única classe. Quando participam da produção capitalista, entram também em outras relações de produção. Em 1970, 5,9 milhões de mulheres estão integradas à produção capitalista $-5,16$ milhões como assalariadas e 675 mil como trabalhadoras independentes. Em toda a França, 11 mil mulheres são "industriais": uma minoria ínfima pertence à classe capitalista, enquanto a maioria das que trabalham pertence à dos proletários. Dentro dessa classe, constituem uma "casta" superexplorada, fato bem conhecido.

Essa superexploração está intimamente ligada à sua exploração específica como mulheres.

De acordo com o que precede, vê-se que é mais ou menos tão certo afirmar que as mulheres de burgueses também são burguesas quanto dizer que o escravo de um agricultor também é agricultor. No entanto, é o que se ouve todos os dias. Do mesmo modo, é costumeira a confusão entre as mulheres de operários e as operárias. Isso quer dizer que, no que diz respeito às mulheres, fundamenta-se seu pertencimento de classe ora em uma definição marxista da classe - em sua relação com a produção -, ora resgatando a definição das mulheres como propriedade e extensão do marido.

Ora, se considerarmos unicamente o modo de produção capitalista como em geral se faz - e aplicarmos às mulheres os mesmos critérios que aos homens, perceberemos que todas as mulheres que não trabalham fora estão, portanto, fora das classes (proletária-capitalista). Por outro lado, só se pode reintegrar as mulheres nas classes ao determinar o pertencimento de classe por meio de critérios não marxistas (pela classe do marido): "A sociedade se divide em classes e as mulheres não estão fora dessas classes, por conseguinte, o destino de cada uma delas coincide com o das outras mulheres e homens que pertencem a essa classe e categoria social" (PCF, 1970).

$\mathrm{Na}$ verdade, ao pretender que as mulheres pertencem à classe do marido, mascara-se exatamente que elas pertencem por definição a uma classe diferente da do marido. Ao pretender que o casamento pode substituir as relações de produção no sistema capitalista como critério de pertencimento de classe nesse sistema, mascara-se tanto a existência de outro sistema de produção quanto o fato de que as relações de produção nesse sistema colocam 
precisamente maridos e mulheres em classes antagônicas (em que uns tiram um proveito material da exploração das outras). Por fim, a "reintegração" das mulheres nas classes por sua definição como propriedade do marido objetiva precisamente velar o fato de que elas são uma propriedade do marido.

Com efeito, se apenas se desejasse associar as mulheres à luta anticapitalista, bastaria demonstrar que, na medida em que está integrada a essa produção (assalariadas), a imensa maioria das mulheres (nove em cada dez trabalhadoras) está objetivamente interessada nessa luta, ao passo que, ao lhes atribuir a classe do marido, considera-se as mulheres dos burgueses (não integradas à produção capitalista) como inimigas. Vê-se, então, que não se trata tanto de associar o conjunto das mulheres à luta anticapitalista, mas de negar a existência de um sistema de produção não capitalista. Ao negar a existência desse sistema, nega-se a existência de relações de produção específicas a ele e se tira das interessadas a possibilidade de se rebelar contra essas relações de produção. Portanto, trata-se, acima de tudo, de preservar o modo de produção patriarcal dos serviços domésticos, isto é, o fornecimento gratuito desses serviços pelas mulheres. A esse respeito, é interessante comparar as teses do PCF, em 1970, às recomendações de Lênin:

A verdadeira libertação da mulher e o verdadeiro comunismo só começarão quando começar a luta das massas (dirigida pelo proletariado que detém o poder) contra essa pequena economia doméstica ou, mais exatamente, no momento de sua transformação maciça em grande economia socialista (Lênin apud Zetkin, 1934).

[Solução do PCF:] Colocar à disposição de todos os lares os aparelhos domésticos que hoje podem levar à mecanização das tarefas domésticas (PCF, 1970).

[Obrigações do patronato e dos poderes públicos segundo o PCF:] Facilitar a tarefa da dona de casa à trabalhadora (PCF, 1970).

[Lênin:] Entre nossos camaradas, há muitos de quem se pode infelizmente dizer: "por baixo do comunista se encontra o filisteu". E uma prova mais evidente disso é o fato de que os homens observam tranquilamente as mulheres se desgastando em um trabalho monótono, extenuante, que absorve seu tempo e suas forças: as tarefas domésticas [...]. Poucos maridos, mesmo entre os proletários, pensam em aliviar um pouco as dificuldades e as preocupações de suas mulheres ou até em liberá-las completamente delas, auxiliando no "trabalho feminino" (Lênin apud Zetkin, 1934). Uma divisão igual no lar das dificuldades e da fadiga é uma concepção limitada da igualdade (PCF, 1970). 


\section{Perspectivas políticas}

Em suma, a exploração patriarcal constitui a opressão comum, específica e principal das mulheres: comum porque atinge todas as mulheres casadas ( $80 \%$ em qualquer momento); específica porque a obrigação de fornecer serviços domésticos gratuitos é só das mulheres; principal porque, mesmo quando elas trabalham "fora", o pertencimento de classe derivado é condicionado por sua exploração enquanto mulheres.

O acesso à propriedade dos meios de produção lhes é proibido pelos regimes matrimoniais (até 1968) e práticas de herança (a maioria das patroas são filhas únicas ou viúvas).

Seu ganho no trabalho assalariado é anulado pela retirada do valor dos serviços venais que são obrigadas a comprar para substituir seus serviços gratuitos.

As condições materiais do exercício da profissão são ditadas por sua exploração patriarcal:

- A própria possibilidade de trabalhar é condicionada pela realização prévia de suas "obrigações familiares", o que resulta ou no impedimento de trabalhar fora, ou na dupla jornada, com o trabalho doméstico;

- As obrigações familiares são consideradas como deficiência e usadas como pretexto pelo capitalismo para explorar as mulheres no trabalho fora de casa.

Neste artigo, não foi possível estudar as relações entre a exploração da força produtiva e da força reprodutiva das mulheres. O controle da reprodução, que é ao mesmo tempo causa e meio da outra grande exploração material das mulheres, a exploração sexual, constitui o segundo aspecto da opressão das mulheres. Estabelecer por que e como essas duas explorações condicionam e reforçam uma à outra e têm o mesmo quadro e o mesmo meio institucional - a família - deve ser um dos primeiros objetivos teóricos do movimento.

Esta análise é preliminar ao estudo das relações entre capitalismo e patriarcado: é preciso saber em que consiste o patriarcado para compreender em que medida ele é teoricamente independente do capitalismo. Apenas essa compreensão permitirá dar conta da independência historicamente constatada entre esses dois sistemas. Só assim é possível basear materialmente a articulação das lutas antipatriarcais e anticapitalistas. Enquanto essa articu- 
lação permanecer baseada em postulados de hierarquia não provada e/ou no voluntarismo ideológico, estaremos nos condenando à confusão teórica e à ineficácia política, no presente, e ao fracasso histórico, no longo prazo.

Essas análises devem ser seguidas das análises de classes que integrem os indivíduos em um ou outro sistema de exploração (patriarcal e capitalista) com base em seus interesses objetivos. Isso é necessário, a curto prazo, para poder proceder à mobilização na luta imediata; a longo prazo, para entender como a dinâmica das lutas antipatriarcais e anticapitalistas poderão ser orientadas para se unirem no combate revolucionário (inútil dizer que isso constitui o objeto de um estudo permanente cujos dados se modificarão sem parar graças à evolução das lutas).

De imediato, pode-se afirmar que a libertação das mulheres não se dará sem a destruição total do sistema de produção e de reprodução patriarcal.

Como esse sistema é central a todas as sociedades conhecidas, essa libertação implica a mudança total das bases de todas essas sociedades, que não ocorrerá sem uma revolução, isto é, a tomada do poder político. Essa tomada de poder deve constituir o objetivo definitivo do movimento de libertação das mulheres, que deve se preparar para uma luta revolucionária.

A mobilização deve se dar a partir da opressão patriarcal e, portanto, incluir todos os indivíduos oprimidos pelo patriarcado e, por essa razão, interessados em sua destruição, ou seja, todas as mulheres! O trabalho de mobilização deve evidenciar a solidariedade de todos os indivíduos oprimidos por um mesmo sistema. Para fazer isso, ele deve:

- atacar os problemas de falsa consciência, a consciência de classe determinada mais pelo pertencimento às classes capitalistas do que às classes patriarcais e à identificação sob esse pretexto à classe patriarcal antagônica;

- mostrar como essa falsa consciência serve aos interesses do patriarcado e prejudica a luta.

Por fim, de imediato, as alianças políticas e táticas do movimento com outros grupos, movimentos ou partidos revolucionários devem ser feitas a partir de sua associação sem ambiguidade aos objetivos do movimento: a partir de sua vontade expressa clara e oficialmente de destruir o patriarcado e de sua participação efetiva no combate revolucionário que tem essa destruição por meta. 


\section{Referências}

BASTIDE, H. (1969). "Les rurales”, La Nef, n. 38.

BENTSON, M. (1969). "The political economy of women's liberation", Monthly Review, 21 (4). Reeditado em TANNER, L. B. (org.) (1970). Voices from women's liberation. New York: Signet Books.

DAYRE, D. (1955). Études et documents du Centre de Recherches Économiques et Sociales, maio.

GIRARD, A. (1958). "Budget-temps de la femme mariée à la campagne", Population, n. 2.

INSEE (1973). Principaux résultats de l'enquête permanente de 1971 sur les conditions de vie des ménages, n. 82.

LARGUIA, I. (1970). "Contre le travail invisible”, Partisans, n. 54-55.

LITTRÉ, E. (1958). Dictionnaire de la langue française. Paris: Gallimard-Hachette.

MANDEL, E. (1962). Traité d'économie marxiste. Paris: Julliard

NOUACER, K. (1969). “Maroc, la ségrégation”, La Nef, n. 38.

PCF - PARTIDO COMUNISTA FRANCÊS (1970). Les communistes et la condition de la femme. Paris: Éditions Sociales.

ROUXIN, C. (1970). Populations et sociétés, n. 23 (mar.).

WITTIG, M.; WITTIG, G.; ROTHENBURG, M. \& STEPHENSON, M. (1970). "Combat pour la liberation de la femme". L'idiot international, n. 6 (maio), p. 12-6.

WOLFELSPERGER, A. (1970). Les biens durables dans le patrimoine du consommateur. Paris: Presses Universitaires de France.

ZETKIN, C. (1934). "Les notes de mon carnet", Lémine tel qu'il fut. Paris: Bureau d'Éditions.

\section{Resumo}

Christine Delphy indica a existência de um modo produção patriarcal, que opera em paralelo ao capitalismo, transferindo sobretrabalho das mulheres para seus maridos. Ela observa em particular dois fenômenos: (1) a permanência de uma boa quantidade de trabalho realizado no âmbito doméstico, mas voltado ao mercado, sobretudo no meio rural, quando a produção das mulheres é apropriada pelos homens; (2) a incoerência de julgar que a produção gerada para o autoconsumo não gera valor. As mulheres, assim, constituem tanto um grupo efetivamente submetido a uma determinada relação de produção, ou seja, uma classe, quanto uma categoria de seres humanos destinados por 
nascimento a entrar nessa classe, ou seja, uma casta. $\mathrm{O}$ artigo discute ainda as diferenças entre a posição da esposa, cujos serviços são remunerados de acordo não com o volume ou qualificação do trabalho, mas com as posses e a boa vontade do marido, e do trabaIhador assalariado.

Palavras-chave: mulheres, trabalho, classes, relações de produção, capitalismo, patriarcado

\section{Abstract}

Christine Delphy indicates the existence of a patriarchal production mode, which operates in parallel to capitalism, transferring women's surplus labor to their husbands. She notes two phenomena in particular: (1) permanence of a good amount of work done within the domestic sphere, but directed to the market, especially in rural areas, when women's production is appropriated by men; (2) incoherence of judging that the output generated for self-consumption does not create value. Thus, women effectively constitute both a group subjected to certain production relations, i. e, a class, and a class of human beings intended by birth to enter that class, i. e., a caste. The article also discusses the differences between the position of a wife, whose services are paid not according to volume or skill level demanded by the work, but with the husband's possessions and good will and waged work.

Keywords: women; work; classes; production relations; capitalism; patriarchy 